\section{Stand Establishment of Fresh-market Tomatoes Sown at High Temperatures}

\author{
Gerald B. Odell' ${ }^{1}$ Daniel J. Cantliffe ${ }^{2}$, Herbert H. Bryan', and \\ Peter J. Stoffella ${ }^{4}$ \\ Vegetable Crops Department, Institute of Food and Agricultural Science, \\ University of Florida, Gainesville, FL 32611
}

Additional index words. gel-mix, germination, Lycopersicon esculentum, plug-mix, pregermination, priming

Abstract. Primed, pregerminated, or nontreated tomato (Lycopersicon esculentum Mill.) seeds were field-sown with several soil amendments to assess stand establishment at high temperatures. Soil amendments did not consistently improve tomato stand establishment. However, covering seeds with a fine-textured calcined montmorillonite clay (Growsorb) resulted in similar or improved total percent emergence, emergence rate, and seedling shoot dry weight as compared to the soil cover (control) for nontreated, primed, or pregerminated seeds. Plug-mix (a peat-vermiculite medium) or gel-mix [a 1:1 mixture (v/v) of plug-mix and gel, starch-acrylate copolymer, or polyacrylate polymer], covered over or mixed with nontreated, primed, or pregerminated seeds, did not consistently improve total percent emergence over the soil cover. However, soil amendments generally resulted in faster emergence than the soil cover. Pregerminated seeds imbibed for 60 or 72 hours at $25 \mathrm{C}$ generally resulted in reduced stands compared to primed or nontreated seeds. Moisturized seeds imbibed for 48 hours at $25 \mathrm{C}$ had faster emergence and heavier seedling shoots than nontreated seeds, regardless of soil amendment. However, primed seeds generally resulted in faster emergence and more plants with heavier seedling shoot weights than nontreated or pregerminated seeds sown at high temperatures.

Erratic emergence of field-sown tomatoes can occur with high soil temperatures, dry seedbeds, or when heavy rains occur shortly after sowing. These extreme environmental conditions often necessitate resowing of uneconomical high amounts of seed to obtain an acceptable plant stand. Even if adequate plant populations are achieved with field sowing in extreme environmental conditions, variations in plant emergence, growth, and development may subsequently reduce uniform maturity and earliness of fruit yields.

Investigations on plant establishment of direct-seeded tomatoes have focused on enhancing stand uniformity in northern latitudes at suboptimal temperatures. Success with fluid drilling pregerminated seed of other vegetable crops (Currah et al., 1974) encouraged researchers to adapt this technique to improve tomato plant establishment. Bussell and Gray (1976) reported that fluid drilling of pregerminated tomato seed reduced mean emergence time, improved total per-

Received for publication 14 Aug. 1991. Accepted for publication 11 Mar. 1992. Florida Agricultural Experiment Station Journal Series no. R-00759. This project was funded in part by grants from the Florida Tomato Exchange. The cost of publishing this paper was defrayed in part by the payment of page charges. Under postal regulations, this paper therefore must be hereby marked advertisement solely to indicate this fact.

${ }^{1}$ Former Graduate Student. Present address: P.0. Box 7063, Ponce, PR 00732

${ }^{2}$ Professor and Chairman.

${ }^{3}$ Professor, Tropical Research and Education Center, 18905 S.W. 280th St., Homestead, FL 33031. ${ }^{4}$ Professor, Agricultural Research and Education Center, P.O. Box 248, Fort Pierce, FL 34954. post-germinative stresses such as soil crust- cent emergence, and reduced variability in emergence time at low temperatures as compared with planting nontreated seeds. Osmotic priming of tomato seeds accelerated seed germination at temperature extremes (Bradford and Murray, 1983; Bussell and Gray, 1976; Ells, 1963; Ode11 and Cantliffe, 1986). Earlier seedling emergence from primed (Leskovar and Sims, 1987; Wolfe and Sims, 1982) or pregerminated (Gray et al., 1979; Taylor, 1977) seeds has led to earlier fruit harvest. However, Alvarado et al. (1987) reported that the earlier growth from primed tomato seeds did not significantly improve early and total yields, or fruit soluble solids content as compared to nontreated seeds.

Soil amendments, such as gels and anticrustants, have been used to reduce pre- and ing and rapid drying of the seed bed (Ells, 1965; Orzolek, 1982). The objectives of our investigations were to determine if tomato seed priming and pregermination in combination with several soil amendments could

Table 1. Daily mean air and soil temperature and rainfall during each experiment. ${ }^{z}$

\begin{tabular}{|c|c|c|c|c|c|c|c|}
\hline \multirow[b]{3}{*}{ Expt. } & \multirow[b]{3}{*}{ Sowing date } & \multicolumn{4}{|c|}{ Temp $\left({ }^{\circ} \mathrm{C}\right)$} & \multicolumn{2}{|c|}{ Rainfall } \\
\hline & & \multicolumn{2}{|c|}{$\operatorname{Air}^{y}$} & \multicolumn{2}{|c|}{ Soilx } & \multirow{2}{*}{$\begin{array}{l}\text { Total } \\
\text { (mm) }\end{array}$} & \multirow{2}{*}{$\begin{array}{c}\text { Daysw } \\
\text { (no.) }\end{array}$} \\
\hline & & Day & Night & Day & Night & & \\
\hline 1 & 13 Sept. 1986 & 31.5 & 20.4 & 46.3 & 22.2 & 13 & 1 \\
\hline 2 & 27 Sept. 1986 & 32.0 & 13.9 & 34.0 & 16.3 & 63 & 2 \\
\hline 3 & 22 July 1987 & 40.5 & 23.2 & 43.5 & 21.2 & 107 & 8 \\
\hline
\end{tabular}

${ }^{2}$ Measurements were made 10 days after each sowing date.

yAir temperatures were measured $46 \mathrm{~cm}$ above the soil surface.

Soil temperatures were measured at a $2-\mathrm{cm}$ depth.

"Number of days precipitation occurred. were pregerminated (radicles $\approx 2 \mathrm{~mm}$ in improve stand establishment under high field temperatures.

Standard experimental procedures. 'FloraDade' tomato seeds were planted on a fine sandy soil (Plummer Series; loamy, siliceous, thermic Ultic Grossarenic Paleoquult) at the Inst. of Food and Agricultural Science Horticulture Unit, Gainesville, Fla., on nonfumigated raised beds. Beds were 30 $\mathrm{cm}$ high, $90 \mathrm{~cm}$ wide, and spaced at $1.5-\mathrm{m}$ centers. Soil (2-cm depth) and air $(46 \mathrm{~cm}$ above the bed surface) temperatures were measured with a recording thermograph for the duration of the experiments, and rainfall was recorded for each of three experiments (Table 1)

Fertilizer was preplant soil-incorporated into the beds at $16.5 \mathrm{~N}, 9.6 \mathrm{P}$, and $18.2 \mathrm{~K}$ $\left(\mathrm{kg} \cdot \mathrm{ha}^{-1}\right)$. If insufficient rainfall $(<1$ $\mathrm{cm} \cdot$ day $^{-1}$ ) occurred, irrigation was applied daily for $1 \mathrm{~h}$ by overhead sprinklers at 12 $\mathrm{mm} \cdot \mathrm{h}^{-1}$.

Seeds were sown in shallow depressions $(2 \mathrm{~cm})$ in the center of each raised bed and then either mixed with or covered by $60 \mathrm{ml}$ of a soil amendment. The same seed lot of 'Floridade' was used for each experiment. Five seeds were sown per depression, which were $30 \mathrm{~cm}$ apart. Each plot consisted of 10 depressions.

Seedling emergence was counted daily, and emergence rate was calculated as mean days to emergence (MDE) (Gerson and Honma 1978). A seedling was considered emerged when both cotyledons were above the soil surface and the hypocotyl was no longer hooked. Shoots from 10 selected seedlings per replication were excised at the soil surface 21 days after sowing, dried at $60 \mathrm{C}$ for a minimum of 5 days, and weighed.

A randomized complete block design was used, with each seed and soil amendment treatment combination replicated four times in each experiment. Analysis of variance (ANOVA) was conducted for each measured or calculated variable. Significant main effect means were partitioned by a least significant difference (LSD) test at $P=0.05$. If a measured trait had a significant soil amendment $\mathrm{x}$ seed treatment interaction, then main effect means were ignored and interaction means were separated by an LSD test at $P=0.05$.

Pregermination $72 h$ (Expt. 1). Seed were pregerminated, primed, or nontreated. Seeds length) in the dark on moistened filter papers 
Table 2. Effects of seed treatments (ST) and soil amendments (SA) on total percent emergence, mean days to emergence (MDE), and seedling shoot dry weight (Expt. 1).

\begin{tabular}{|c|c|c|c|c|c|c|c|}
\hline \multirow[b]{2}{*}{ Variable } & \multicolumn{3}{|c|}{ Total emergence (\%) } & \multicolumn{3}{|c|}{ MDE (days) } & \multirow{2}{*}{$\begin{array}{l}\text { Shoot wt } \\
\text { (mg/plant) }\end{array}$} \\
\hline & Nontreated & Primed & germinated & Nontreat & Primed & Pregerminated & \\
\hline \multicolumn{8}{|l|}{$\overline{\mathrm{SA}}$} \\
\hline Soil & 82.5 & 75.0 & 0 & 7.8 & 5.5 & $\ldots$ & 141 \\
\hline Plug-mix & 52.0 & 51.0 & 9.5 & 7.7 & 5.5 & 6.7 & 169 \\
\hline Liquagel gel-mix & 68.0 & 51.5 & 10.0 & 6.4 & 5.5 & 7.2 & 120 \\
\hline Growsorb & 81.5 & 77.5 & 14.0 & 6.7 & 5.9 & 5.5 & 105 \\
\hline LSD $(0.05)$ & & & & & & & 39 \\
\hline \multicolumn{8}{|l|}{ ST } \\
\hline Nontreated & & & & & & & 104 \\
\hline Primed & & & & & & & 163 \\
\hline Analysis of variance & $\mathrm{df}^{\mathbf{y}}$ & & & & & & \\
\hline \multicolumn{8}{|l|}{ Significance } \\
\hline SA & 3 & ** & & & ** & & * \\
\hline ST & $2(1)$ & ** & & & NS & & * \\
\hline $\mathbf{S A} \times \mathbf{S T}^{\mathbf{x}}$ & $6(3)$ & ** & & & $*$ & & NS \\
\hline
\end{tabular}

${ }^{z}$ Mean dry weights are pooled over nontreated and primed seed treatments.

$y$ Values in parentheses indicate degrees of freedom for shoot weight.

xignificant SA $\times$ ST interaction means were separated by $L S D, P=0.05 . L^{2} D_{0.05}$ values are $17.1 \%$ for emergence and 0.8 days for MDE.

NS,*,**Nonsignificant or significant at $P=0.05$ or 0.01 , respectively.

Table 3. Effects of seed treatments (ST) and soil amendments (SA) on total percent emergence and mean days to emergence (MDE) (Expt. 2).

\begin{tabular}{|c|c|c|c|c|c|c|c|}
\hline \multirow[b]{2}{*}{ SA } & \multirow{2}{*}{$\begin{array}{c}\text { Sced } \\
\text { placement }\end{array}$} & \multicolumn{3}{|c|}{ Total emergence $(\%)$} & \multicolumn{3}{|c|}{ MDE (days) } \\
\hline & & Nontreated & Primed & Pregerminated & Nontreated & Primed & Pregerminated \\
\hline Soil & Covered & 53.5 & 80.5 & 2.5 & 8.6 & 6.8 & 9.4 \\
\hline Plug-mix & Covered & 56.0 & 77.0 & 11.0 & 7.9 & 5.8 & 7.8 \\
\hline \multirow{2}{*}{ Liquagel gel-mix } & Covered & 63.0 & 77.5 & 18.5 & 7.2 & 5.4 & 7.0 \\
\hline & Mixed & 47.0 & 54.0 & 58.5 & 7.1 & 5.3 & 5.0 \\
\hline \multirow[t]{2}{*}{ Viterra II gel-mix } & Covered & 63.5 & 78.0 & 51.0 & 7.0 & 5.0 & 5.8 \\
\hline & Mixed & 66.0 & 66.5 & 51.0 & 6.5 & 5.1 & 4.9 \\
\hline Growsorb & Covered & 72.5 & 77.5 & 22.5 & 7.9 & 6.1 & 8.9 \\
\hline \multicolumn{8}{|l|}{$\begin{array}{l}\text { Analysis of variance } \\
\text { Significance }\end{array}$} \\
\hline SA & 6 & & $* *$ & & & $* *$ & \\
\hline $\mathrm{ST}$ & 2 & & ** & & & ** & \\
\hline $\mathrm{SA} \times \mathrm{ST}^{\mathbf{z}}$ & 12 & & $* *$ & & & $* *$ & \\
\hline
\end{tabular}

${ }^{2} \mathrm{SA} \times \mathrm{ST}$ interaction means were separated by $\mathrm{LSD}, P=0.05 . \mathrm{LSD}_{0.03}$ values are $19.2 \%$ for emergence and 0.7 days for MDE.

**Significant at $P=0.01$.

Table 4. Effects of seed treatments (ST) and soil amendments (SA) on mean days to cmergenec (MDE) and seedling shoot dry weight (Expt. 3).

\begin{tabular}{|c|c|c|c|c|c|}
\hline \multirow[b]{3}{*}{ - } & \multicolumn{3}{|c|}{$\mathrm{MDE}$} & \multirow{3}{*}{$\begin{array}{c}\text { Emergence } \\
(\%)\end{array}$} & \multirow{3}{*}{$\begin{array}{l}\text { Shoot wt } \\
\text { (mg/plant) }\end{array}$} \\
\hline & \multicolumn{3}{|c|}{$\mathrm{ST}$} & & \\
\hline & Nontreated & Primed & Moisturized & & \\
\hline \multicolumn{6}{|l|}{ SA } \\
\hline Soil & 7.9 & 4.9 & 5.7 & 63.2 & 84 \\
\hline Plug-mix & 5.8 & 4.1 & 4.5 & 60.5 & 172 \\
\hline Viterra NT/L gel-mix & 5.2 & 3.8 & 4.0 & 73.5 & 253 \\
\hline Plug-mix + dry gel (Viterra NT/L) & 5.6 & 3.9 & 4.2 & 65.2 & 200 \\
\hline Growsorb & 5.9 & 4.2 & 5.0 & 74.7 & 146 \\
\hline Viterra NT/L gel-mix + Growsorb & 5.0 & 4.0 & 4.0 & 78.3 & 207 \\
\hline LSD $(0.05)$ & & & & 11.8 & 36 \\
\hline \multicolumn{6}{|l|}{ ST } \\
\hline Nontreated & & & & 66.8 & 127 \\
\hline Primed & & & & 70.8 & 215 \\
\hline Moisturized & & & & 70.1 & 189 \\
\hline LSD $(0.05)$ & & & & & 26 \\
\hline Source of variation & $\mathrm{df}$ & & & & \\
\hline \multicolumn{6}{|l|}{ Significance } \\
\hline SA & 5 & $* *$ & & $*$ & $* *$ \\
\hline ST & 2 & ** & & NS & ** \\
\hline $\mathrm{SA} \times \mathrm{ST}^{\mathrm{z}}$ & 10 & $* *$ & & NS & NS \\
\hline
\end{tabular}

${ }^{2} \mathrm{SA} \times \mathrm{ST}$ interaction means were separated by LSD, $P=0.05 . \mathrm{LSD}_{0.03}$ value for MDE is 0.4 days. NS,*,**Nonsignificant or significant at $P=0.05$ or 0.01 , respectively. in petri dishes ( $9 \mathrm{~cm}$ in diameter) for $72 \mathrm{~h}$ at $25 \mathrm{C}$. Seeds were primed in an aerated solution of $1.5 \% \mathrm{~K}_{3} \mathrm{PO}_{4}+1 \% \mathrm{KNO}_{3}$ for 6 days at $25 \mathrm{C}$ in the dark and then dried to $\approx 6 \%$ moisture at $10 \mathrm{C}$ and $45 \%$ relative humidity (Odell and Cantliffe, 1986).

Soil amendment treatments were plug-mix, a peat-vermiculite potting medium (W.R. Grace Co., Cambridge, Mass.); gel-mix, a $1: 1$ mixture $(\mathrm{v} / \mathrm{v})$ of plug-mix and a $0.75 \%$ solution of Liquagel, a hydrophilic starchacrylate copolymer (Grain Processing, Muscatine, Iowa); and Growsorb as LVM 24/48, a fine-textured, calcined montmorillonite clay (Mid Florida Mining, Lowell, Fla.). A cover of sandy field soil served as the control. Soil amendments were applied as covers over the seeds of each treatment. Pregerminated seeds were sown manually in a $0.55 \%$ Liquagel (3 $\mathrm{ml} /$ five seeds) before being covered by the soil amendments and irrigated.

Pregermination $60 \mathrm{~h}$ (Expt. 2). Seeds were primed, pregerminated, or nontreated. Priming and pregermination of seeds were identical to procedures described in Expt. 1. Imbibition time for pregerminated seeds $(50 \%$ of seeds with visible radicles) was $60 \mathrm{~h}$, since $72 \mathrm{~h}$ reduced emergence in Expt. 1.

Soil amendments were as described in Expt. 1 with the addition of Viterra II gel-mix, a $1: 1$ mixture $(\mathrm{v} / \mathrm{v})$ of plug-mix and a $0.55 \%$ solution of Viterra II gel, a hydophilic polyacrylate polymer (Nepera, Harriman, N.Y.). Soil (control) or soil amendments were applied over the seeds. Seeds were also mixed with Liquagel gel-mix and Viterra II gel-mix before field sowing. Seedling shoot dry weights were not measured due to severe damping-off and insect damage that occurred during the 3 rd week after sowing.

Pregermination $48 h$ (Expt. 3). Seed treatments were nontreated, primed, or moisturized. Primed seeds were prepared as described in Expt. 1. Imbibition time for moisturized seeds (minimal seeds with visible radicles) was reduced to $48 \mathrm{~h}$ in an attempt to further improve emergence.

Soil amendments were plug-mix; Viterra NT/L gel-mix (a finer particle preparation of Viterra II); plug-mix plus dry gel (5.5 g Viterra NT/L); plug-mix moistened with $70 \mathrm{ml}$ of water; Growsorb; and gel-mix plus Growsorb as LVM 24/48. Seeds were sown in 30$\mathrm{ml}$ aliquots of Viterra gel-mix, then covered with $30 \mathrm{ml}$ Growsorb. A cover of field soil served as the control.

Growsorb amendments and soil were applied as covers over the top of each seed treatment. Due to reduced imbibition time (48 vs. 60 or 72 h), moisturized seed treatment had few seeds with protruding radicles. Therefore, incorporating the moisturized seeds in a protective gel was not necessary before covering them with soil or Growsorb. All other soil amendments were applied with the seeds previously incorporated.

Daily soil temperatures averaged higher than $40 \mathrm{C}$ during the 10 days following sowing in Expt. 1 (Table 1). Planting germinated seeds with exposed radicles (pregerminated seed treatment) into a hot soil drastically reduced total percent emergence as compared 
with nontreated or primed seeds (Table 2).

Seed treatment $\times$ soil amendment interactions were significant for MDE and total percent emergence (Table 2). Nontreated or primed seeds covered with soil or Growsorb had similar total percent emergence (Table 2 ). However, total percent emergence was significantly lower if primed seeds were covered with plug-mix or Liquagel gel-mix as compared with soil or Growsorb. MDE was similar for all soil amendments for primed seeds. However, nontreated seeds covered with Liquagel gel-mix or Growsorb exhibited reduced MDE as compared to the soil cover.

Since percent emergence from pregerminated seeds was low, a sufficient number of plants could not be sampled for seedling dry weight measurements. However, primed seeds had produced heavier seedling shoots than nontreated seeds by 21 days after sowing (Table 2). Seeds covered with plug-mix produced heavier seedling shoots as compared with the other soil amendment treatments, except for the soil cover.

Seed treatment $\times$ soil amendment interactions were significant for MDE and total percent emergence in Expt. 2 (Table 3). Priming of seeds resulted in a higher total percent emergence than their pregermination, except when seeds were mixed in gelmix. Soil amendments did not improve total percent emergence for nontreated or primed seeds as compared with the soil cover. However, each soil amendment, except for plugmix and Liquagel gel-mix covers, increased total percent emergence from pregerminated seeds relative to the soil cover. Primed seeds emerged faster than nontreated seeds, regardless of soil amendment. Each soil amendment, except for plug-mix cover of nontreated seeds and Growsorb cover for each seed treatment, resulted in a faster emergence than the soil cover. Total percent emergence or MDE for nontreated seeds were similar between mixed or cover treatments of Liquagel gel-mix or Viterra II gel-mix.

Soil amendment $\times$ seed treatment interaction was significant for MDE in Expt. 3 (Table 4). Primed seeds emerged more rapidly than nontreated seeds, regardless of soil amendment, and more rapidly than pregerminated seeds with soil or Growsorb covers.
Each soil amendment resulted in faster emergence than the soil cover, regardless of seed treatment. Therefore, the soil amendment $x$ seed treatment interaction was attributed to differential MDE responses within soil amendment treatments, other than the soil cover. Shoot weights were significantly higher for seedlings from primed seeds than from nontreated or pregerminated seeds (Table 4). Each soil amendment improved seedling shoot weight as compared with the soil cover.

Tomato seeds with exposed radicles may be more sensitive to high soil temperatures, regardless of soil amendment, than nontreated or primed seeds without exposed radicles. Similarly, fluid drilling of pregerminated seeds or gel treatments applied in hot, dry conditions resulted in poorer plant establishment than under cool, moist conditions for several crucifers (Kahn and Motes, 1988, 1989; Perkins-Veazie and Cantliffe, 1989). Our data indicate that priming of tomato seeds generally improved stand establishment under high temperature conditions relative to pregermination or no seed treatment. Soil amendments. did not consistently improve stand establishment of tomatoes under hightemperature conditions. However, total percent emergence was similar or improved with Growsorb soil amendment, and faster emergence generally occurred for most soil amendments as compared with the soil cover, regardless of seed treatment. These results are useful to tomato producers who must obtain plant emergence under high temperatures, as found in Florida, in that soil amendments, such as Growsorb, will overcome problems with soil compaction, poor aeration, and water logging that commonly occur in summer and fall in Florida's sandy soils. The use of primed seed will overcome thermo-inhibition of the tomato seed; thus, the combination of amendment and priming will ensure more rapid, uniform stands under these stressful conditions.

\section{Literature Cited}

Alvarado, A.D., K.J. Bradford, and J.A. Hewitt. 1987. Osmotic priming of tomato seeds: Effects on germination, field emergence, seedling growth, and fruit yield. J. Amer. Soc. Hort. Sci. 112:427-432.

Bradford, K.J. and M. Murray. 1983. Priming tomato seed. Amer. Veg. Grower 31:14-16.

Bussell, W.T. and D. Gray. 1976. Effects of presowing seed treatments and temperatures on tomato seed germination and seedling emergence. Scientia Hort. 5:101-109.

Currah, I.E., D. Gray, and T.H. Thomas. 1974. The sowing of germinating vegetable seeds using a fluid drill. Ann. Applied Biol. 76:311-318.

Ells, J.E. 1963. The influence of treating tomato seed with nutrient solutions on emergence rate and seedling growth. Proc. Amer. Soc. Hort. Sci. 83:684-687.

Ells, J.E. 1965. Prevention of stand losses in tomato due to soil crust formation. Proc. Amer. Soc. Hort. Sci. 87:433-436.

Gerson, R. and S. Honma. 1978. Emergence response of the pepper at low soil temperature. Euphytica 27:151--156.

Gray, D.J., R.D. Steckel, and J.A. Ward. 1979. The effects of fluid sowing pre-germinated seeds and transplanting on emergence, growth and yield of outdoor bush tomatoes. J. Agr. Sci. (Cambridge) 93:223-233.

Kahn, B.A. and J.E. Motes. 1988. Comparison of fluid drilling with conventional planting methods for stand establishment and-yield of spring and fall broccoli crops. J. Amer. Soc. Hort. Sci. 113:670-674.

Kahn, B.A. and J.E. Motes. 1989. Comparison of fluid drilling with conventional planting methods for stand establishment and yield of spring and fall cauliflower crops. J. Amer. Soc. Hort. Sci. 114:200-204.

Leskovar, D.K. and W.L. Sims. 1987. Emergence and yield of tomato (Lycopersicon esculentu $m$ Mill.) in response to presowing treatments. Acta Hort. 200:145-152.

Odell, G.B. and D.J. Cantliffe. 1986. Seed priming procedures and the effect of subsequent storage on the germination of fresh market tomato seeds. Proc. Fla. State Hort. Soc. 99:303306.

Orzolek, M.D. 1982. Effects of gels and anticrustants on the emergence and yield of tomatoes. Veg. Res. Rpt. Pennsylvania State Univ. p. 54-56.

Perkins-Veazie, P.M. and D.J. Cantliffe. 1989. Improved stand establishment of direct-seeded cabbage with seed covers. J. Amer. Soc. Hort. Sci. 114:36-39.

Taylor, A.G. 1977. Comparative performance of pregerminated, high moisture content and dry vegetable seed in greenhouse and field studies. J. Seed Technol. 2:52-61.

Wolfe, D.W. and W.L. Sims. 1982. Effects of osmoconditioning and fluid drilling of tomato seed on emergence rate and final yield. HortScience 17:936-937. 